\title{
Impact Perforation of aluminum Cymat Foam
}

\author{
Ibrahim Elnasri ${ }^{1,2, *}$, Han Zhao ${ }^{3}$ \\ ${ }^{1}$ LGM, Ecole Nationale d'Ingénieurs de Monastir, Université de Monastir, Av. Ibn ElJazzar, Monatir 5019, Tunisia \\ ${ }^{2}$ FOE, University of Tabuk,P.O. Box 741, Tabuk, Kingdom of Saudi Arabia \\ ${ }^{3}$ LMT, CNRS, Université Paris-Saclay, 61, Av. Du president Wilson, 94230, Cachan, France
}

\begin{abstract}
The behavior of aluminum Cymat foam under impact perforation loading was studied using experiments and simulations. Measurements at $40 \mathrm{~m} / \mathrm{s}$ were performed with an inverse perforation setup using a Split Hopkinson Pressure Bars system. Such measurement is missing in a classical free-flying penetrator-immobile-target scheme under impact loading and makes it possible to directly compare impact the perforation force-displacement curves with the static ones. Compared with quasi-static test perforation forces obtained under the same geometry and clamping system, a significantly enhanced perforation force was found under impact loading. Numerical simulations of the perforation test were developed using LSDYNA finite element code to provide the local information necessary to understand the unexpected enhancement in perforation force. The shock effect was found to be responsible for enhancement of the perforation force and revealed that the honeycomb model with appropriate tensile failure criteria was more suitable for model perforation of the foam than the Deshpande and Fleck model with volumetric failure strain criteria
\end{abstract}

\section{Introduction}

The impact behaviour of cellular material (foam, honeycomb, hollow spheres) have gained scientific interest recently because of their excellent properties such as specific resistances and high specific energy absorption capacities. The static indentation and penetration properties of metal foams have been examined by Olurin et al. [1] and Andrews et al. [2]. These studies determined that plastic deformation was concentrated in the region directly underneath the penetrator.

Common penetration tests at lower velocity $(<10$ $\mathrm{m} / \mathrm{s}$ ) could be performed using drop weights with a perforator [3-4]. The basic measurement in this case is the deceleration of the impact mass, estimated by an accelerometer. The force-displacement curves are hardly available. However, the common testing technique at higher velocity consists in launching a free flying projectile against an immobile target using a gas gun [56]. The main measurements recorded were velocities before and after perforation of the foam and was a lack of completely perforating force-displacement history. One can only determine the global energy absorbed during perforation and this makes it very difficult to understand what happened during the high-speed perforation processes.

Ramachandra et al. [6] performed penetration tests using an air gun that launched flat-ended bullets at samples supported on a metallic backing plate with impact velocities ranging from 22 to $30 \mathrm{~m} / \mathrm{s}$. The analysis showed a significant increase in the absorbed energy per unit volume when the impact velocity was greater than $10 \mathrm{~m} / \mathrm{s}$, which was attributed to the shock enhancement effect. $\mathrm{Li}$ et al. [7] performed dynamic indentation and penetration tests on closed-cell aluminum foam with a flat-end punch indenter at impact velocities ranging from 20 to $120 \mathrm{~m} / \mathrm{s}$. The impact velocity affected the size of localized deformation and the total energy absorbed, which was also attributed to the shock effect. Lu et al. [8] studied the dynamic indentation and penetration of aluminum foams using Abaqus finite element analysis, introducing cohesive elements to model the tear energy. They used plastic structural shock theory to calculate the resistance force with indentation depth during indentation processes, but no experimental work was carried out.

The finite element method is a powerful tool for the development and optimization of new structural components; however, modeling the impact perforation of aluminum foam core poses several challenges, such as modeling of constitutive material of more compressible foam and the fracturing of elements cell. Various constitutive models for metallic foams have been proposed over the years for use in numerical simulations. Existing models can be divided into two major groups. Models in the first group use the principal stresses to determine the yielding of the foam [9-11]. There are a number of material models implemented in LS-DYNA and this family of models includes, for example material

Corresponding author: ibrahim.nasri@issig.rnu.tn 
honeycomb (MAT-26), material isotropic crushable foam (MAT-63), and material modified honeycomb (MAT-126). Models in the second group use the first and second stress invariants to determine yielding of the foam [12, 13-18]. The models whose yield functions included second-order terms were developed by Deshpande and Fleck [12]. Zhang [16], Miller [17], and Gibson [18]. Examples of models implemented in LSDYNA using this type of yielding are the Deshpande and Fleck model (MAT-154) and the Drucker-Prager Model (MAT-193).

Fang et al. [19] developed a new constitutive model of aluminum foam, which accounts for volumes changes under hydrostatic compression and combines the hydrostatic pressure and von Mises stress into one yield stress. This model was validated in crush simulations of foam-filled columns with square and hexagonal crosssections. However, Hanssen et al. [20] evaluated the models MAT-26, MAT-63, and MAT-154 and found that none of them could predict, with convincing accuracy, the behavior of metallic foam compared with different experimental data. They suggested that fracture of the foam is a very likely local and/or global failure mechanism, which was not taken into account in any of the models evaluated. Reyes et al. [21] implemented two fracture criteria in the Deshpande and Fleck model [12]: a volumetric strain fracture based criterion that accounts for hydrostatic deformation and an energy based criterion that takes into account the deviatoric deformation in the fracture of the foam cells. However, it was concluded that the energy based criterion is more suitable for the indentation test than the volumetric strain fracture criterion and that the critical energy value of $\mathrm{W}$ may be problem dependent and may thus need to be selected based on experience or validation studies using experimental data.

This paper deals with the behaviour of aluminum Cymat foam under impact perforation loading. Perforation behavior under static and dynamic loading (performed using a newly developed inverse perforation test with a Hopkinson pressure bar) was measured and the absorption energy of the studied foam was determined. The perforation force was significantly enhanced during dynamic loading as compared to static loading. Numerical simulations were carried out using the finite element software LS-DYNA to investigate possible differences in component interactions between quasi-static and impact loading that might explain the enhancement of the perforation force

\section{Experimental setup}

The inverse perforation method with Hopkinson pressure bars was adopted to study the aluminum Cymat foam sample under impact loading. It consisted of shooting a sample against a long instrumented Hopkinson bar.

The inversed perforation testing setup used a gas gun with a 70-mm-inner-diameter barrel and a 16-mmdiameter and 6-m-long rod with a semi-spherical nose at its perforating end. The rod is instrumented by strain gauges with the aim of obtaining accurate force measurements during the whole of the perforation process. Figure 1 shows an outline of the experimental setup. Zhao et al. [22] present details regarding the theory of this method (e.g., piercing force vs. displacement history). Quasi-static tests were also performed using a universal testing machine to study the effect of the loading rate on foam perforation. Perforation tests were performed at controlled speeds $(0.1 \mathrm{~mm} / \mathrm{s})$. The piercing forces were recorded with a load cell machine and the displacement was obtained from the test machine measurements.

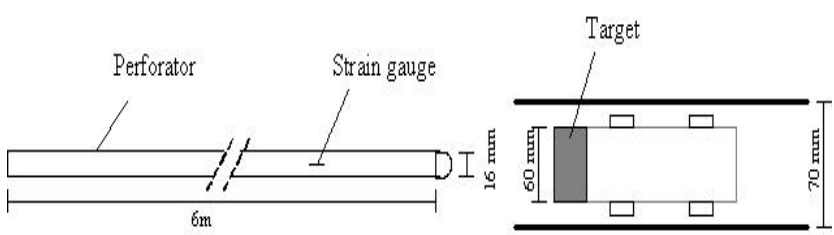

Fig. 1. Experimental set-up for the inversed perforation test.

\subsection{Samples}

The studied samples were cylinders of aluminum Cymat foam $60 \mathrm{~mm}$ in diameter and $40 \mathrm{~mm}$ thick. Aluminum Cymat is a potential material for Airbus aircrafts when integrated in sandwich samples. A typical quasi-static stress-strain curve is shown in Figure 2.

Table 1 provides a summary of the basic characteristics of the aluminum Cymat foam. The flow stress given in Table 1 is defined as the average yield stress under quasi-static loading. The behavior of aluminum foam has been investigated under quasi-static and impact loading by Zhao et al. [23] and Elnasri el al. [24]. They concluded that despite significant scatter, the rate sensitivity was quite small for low impact velocities and a large enhancement of the strength was observed under moderate impact velocities. The geometric samples were similar to those used in the foam perforation experiments.

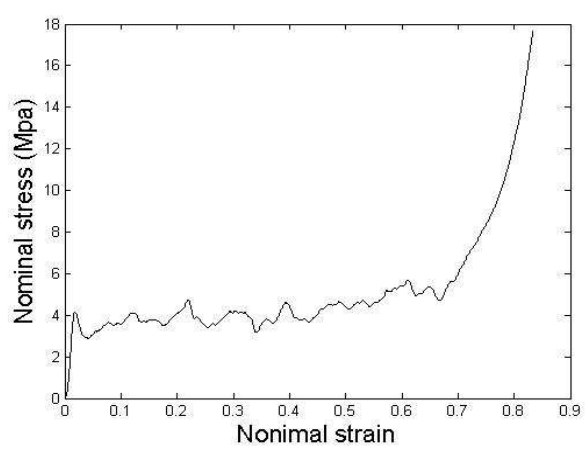

Fig. 2. Typical quasi-static stress-strain curve foam.

Table 1. Quasi-static basic mechanical data of Cymat foam.

\begin{tabular}{|c|c|c|c|}
\hline Materials & $\begin{array}{c}\text { Density } \\
(\mathbf{k g} / \mathbf{m 3})\end{array}$ & Locking strain & $\begin{array}{c}\text { Flow stress } \\
\text { (MPa) }\end{array}$ \\
\hline Cymat foam & 235 & 0.68 & 4 \\
\hline
\end{tabular}




\subsection{Experimental results}

Inverse perforation tests at $40 \mathrm{~m} / \mathrm{s}$ and under quasi-static loading were performed on the aluminum Cymat foam sample. Figure 3 illustrates the difference between quasistatic and impact perforation at about $40 \mathrm{~m} / \mathrm{s}$. Figure 4 shows the foam perforation under quasi-static loading. The presence of holes in the foam illustrates that perforation was occurring.

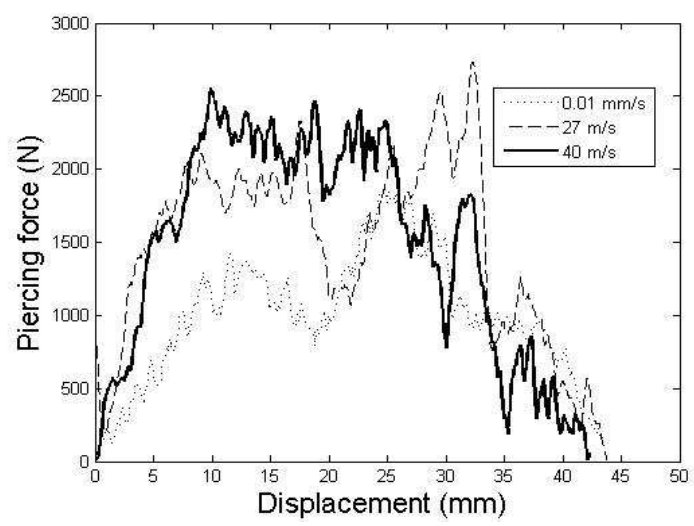

Fig. 3. Comparison between quasi-static and impact perforating force for aluminum Cymat foam.

Comparisons of static and impact perforation tests showed a significant enhancement of the piercing curve under impact loading. Due to the small number of received samples, only one impact test at about $27 \mathrm{~m} / \mathrm{s}$ and one at about $40 \mathrm{~m} / \mathrm{s}$ were performed. The scatter found in impact tests was quite high. However, the sample masses and foam core densities varied between samples. In order to reduce such a mass density effect, an affine correction with respect to mass density was applied.

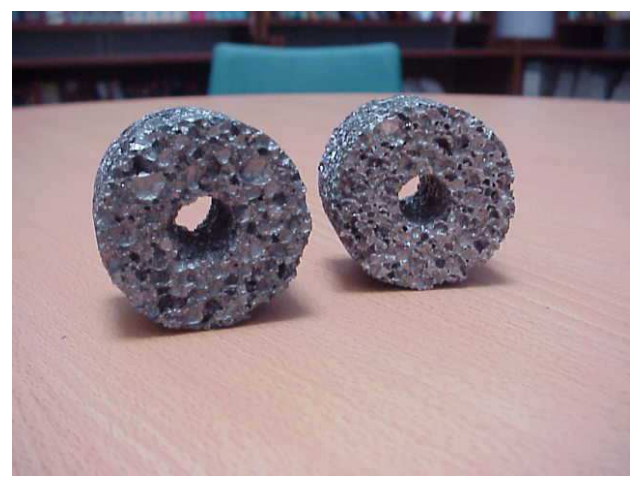

Fig. 4. Photograph of Cymat foam after static perforation.

Another interesting feature was the energy absorption capacity. We define the absorbed energy for the dynamic perforation using the following equation:

$$
E(u)=\int_{0}^{U} F d u
$$

where $\mathrm{u}$ is the penetrating displacement and $\mathrm{F}$ the measured force on the pressure bar. The energy absorption is plotted in Figure 5. It shows that the absorbed energy during impact perforation was higher than during quasi-static perforation. Enhancement under impact loading was evident and averaged about $50 \%$.

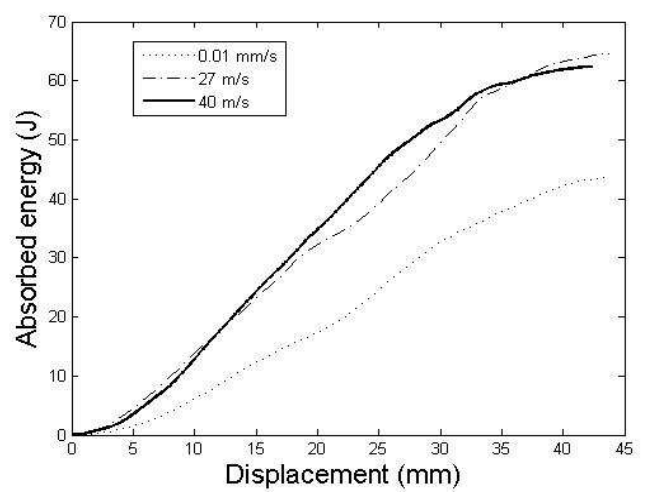

Fig. 5. Absorbed energy vs. displacement curves.

The energy enhancement found for the impact piercing force is quite surprising because the rate sensitivity of foam at low impact velocity is known to be quite small. As there was no means of obtaining more detailed experimental evidence, a numerical model was developed to investigate this enhancement.

\section{Numerical simulation model}

\subsection{Finite element model}

Explicit LS-DYNA code [25] was used to investigate the dynamic perforation of the aluminum foam. Figure 6 shows the numerical model of the impact perforation setup, which consists of four parts. The foam is clamped between two rigid parts by six bolts. The hollow tubular aluminum projectile (part 4) and the aluminum clamping ring (part 2) are modeled as rigid bodies by the material type $20 *$ (MAT_RIGID) in LS-DYNA. Rigid parts are merged into one (part 4) via the LS-DYNA command *CONSTRAINED_RIGID_BODIES. The perforator is represented as the elastic part by the material type $1 *$ (MAT_ELASTIC, density $=8050 \mathrm{Kg} / \mathrm{m}^{3}$, Young's modulus $=188 \mathrm{GPa}$, Poisson's ratio $=0.3$ ). The foam is modeled using brick elements. The numerical model consists of 37614 nodes, 30592 3-D elements comprising 4992 for the perforator part, 1600 for the rigid part, and 24000 brick elements for the foam. A refined mesh is generated within the penetration area just under the perforator. Eroding surface-to-surface contact was established between the perforator and the foam. Soft constraint-based contact was applied. No-friction contact is assumed in all simulations. Single integrated point meshes are adopted in the model. An hourglass control card is used to remove the hourglass modes. The degrees of freedom in z-translation and z-rotation of the perforator are fixed at the no-impact end. The velocity of the foam and the projectile are set as initial velocity nodes. 


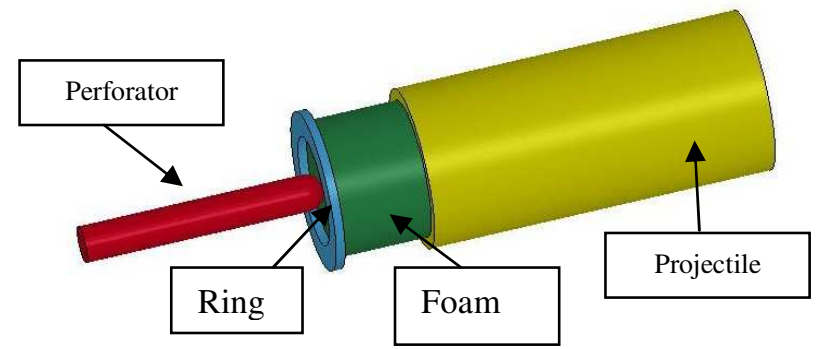

Fig. 6. Numerical model for the perforation of aluminum Cymat foam.

\subsection{Finite element model validation of the aluminum foam}

Behaviour laws are implemented in LS-DYNA code to model the foam behaviour under impact .To choose which constitutive law best models the foams under impact perforation, we studied the honeycomb and Deshpande and Fleck models. We tested these models because they are both suitable for the complex perforation test and can integrate failure criteria.

\subsubsection{Honeycomb model (MAT_26)}

The Honeycomb model input requires the compression behavior of curves and shear in three directions. Isotropic behaviour was assumed by taking the same properties in all orthogonal directions in this model. The erosion of elements is found using the tensile failure strain. The constitutive properties of the foam are: $\mathrm{E}=70$ $\mathrm{GPa}$, Poisson's ration $=0.3$, Yield stress $=240 \mathrm{MPa}$, $\mathrm{EEAU}=\mathrm{EBBU}=\mathrm{ECCU}=300 \mathrm{MPa}$, tensile strain at failure $=0.05, \mathrm{ABU}=\mathrm{GBCU}=\mathrm{GCAU}=140 \mathrm{MPa}$ [26].

\subsubsection{Deshpande and Fleck model (MAT_154)}

The Deshpande and Fleck model gives the relation between an equivalent stress and an equivalent strain depending on a criterion shape parameter $\alpha$. The equivalent stress and strain relation available in LSDYNA is an empirical one with several parameters to be determined. The model parameters are identified using uniaxial compression. The identified parameter are : $\mathrm{E}=$ $229 \mathrm{MPa}, \sigma_{\mathrm{pl}}=3.17 \mathrm{MPa}, \gamma=2.26 \mathrm{MPa}, \alpha_{2}=30.24 \mathrm{MPa}$, $\beta=11.8, \quad \varepsilon_{\mathrm{d}}=2.44$, volumetric strain=0.1. A fully integrated solid element is used. We observed that when we used the default eight-node brick element of LSDYNA [26] with a one-point reduced integration scheme, the analyses gave unphysical results.

\subsubsection{Selection of finite element model of the foam}

Impact tests were performed at $40 \mathrm{~m} / \mathrm{s}$ with the two models. The simulation results are shown in Figure 7. It is observed that the volumetric strain-erosion criterion to predict fracture is not physically reasonable for the Deshpande and Fleck model. Simulations with the honeycomb model and tensile failure criteria reproduce the elastic, plastic, and fracture phases more accurately than simulations with the Deshpande and Fleck model. This is due to the use of the volumetric strain based criterion in modeling the erosion of the elements, because only the hydrostatic deformation is included in this criterion. In reality, deviatoric deformation can also cause fractures. Therefore, it was decided to use the honeycomb model as a constitutive model for foam modelling rather than Deshpande and Fleck model. The choice was motivated by the relative simplicity of the model and the fact that Deshpande and Fleck model is more realistic for crushing behaviour.

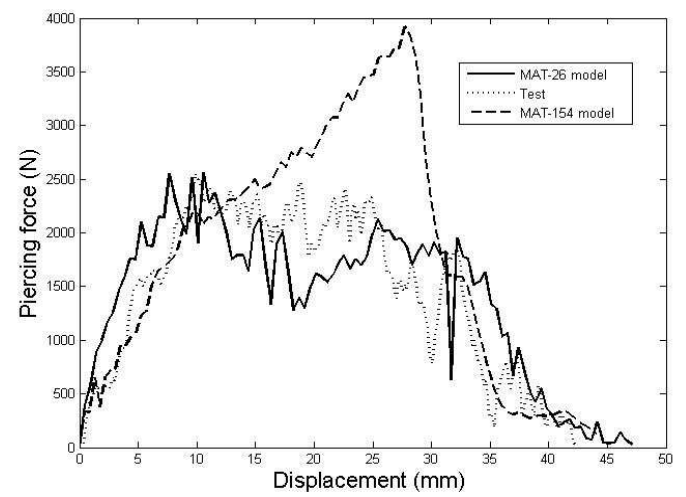

Fig. 7. Comparison between experimental and simulated perforating force vs. displacement curves (MAT_26 and MAT_154).

\section{Numerical results}

Figure 8 show the simulated piercing-force displacement curves at $40 \mathrm{~m} / \mathrm{s}$. compared with the experimental results. The piercing force is obtained by using the command *Database_Nodal_Force_Group. All nodes on the perforated end were integrated into the group nodes, which can be compared to the piercing force recorded by the strain gauge instrumented on the SHPB. It was observed that the simulated piercing curves were in good agreement with experiments.

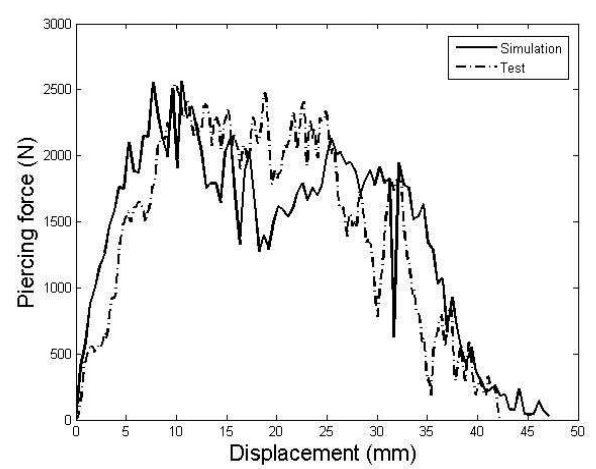

Fig. 8. Comparison between experimental and simulated perforating force vs. displacement curves $(\mathrm{v}=40 \mathrm{~m} / \mathrm{s})$. 


\section{Analysis and discussions}

\subsection{Virtual numerical test}

The numerical models provide virtual tests that yield detailed information not available during physical testing (e.g., strain, stress, etc.). Five numerical tests of quasistatic to dynamic loading up to an impact velocity of 200 $\mathrm{m} / \mathrm{s}$ (i.e., 40, 100, 140, $200 \mathrm{~m} / \mathrm{s}$ ) were conducted. The results are given in Figure 9. The piercing peak force increases regularly with impact speed.

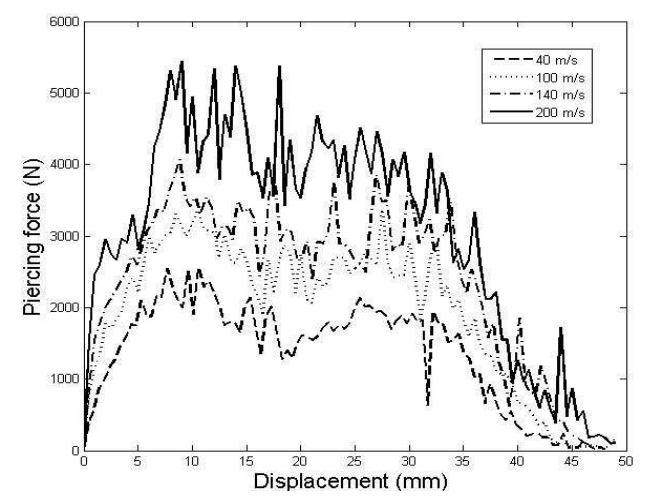

Fig. 9. Quasi-static and dynamic simulated perforating force vs. displacement curves $(v=40,100,160,200 \mathrm{~m} / \mathrm{s})$.

Differences between static and dynamic loading give insight into the cause of the force enhancement. To this end, effective stresses were checked between static and dynamic loading on all elements under the semispherical end (20 elements). It is interesting to analyze their effective stresses. The effective stress evolution versus displacement under quasi-static and dynamic loading (static, 40, 100, $200 \mathrm{~m} / \mathrm{s}$ ) is depicted in Figure 10. The effective stress strength under dynamic loading is higher than during quasi-static loading. The effective stress increases with impact velocity. This demonstrates that the enhancement of the effective stress when the impact velocity increases is due to propagation of the front shock on the sample, and this may be because the aluminum Cymat foam is rate-insensitive.

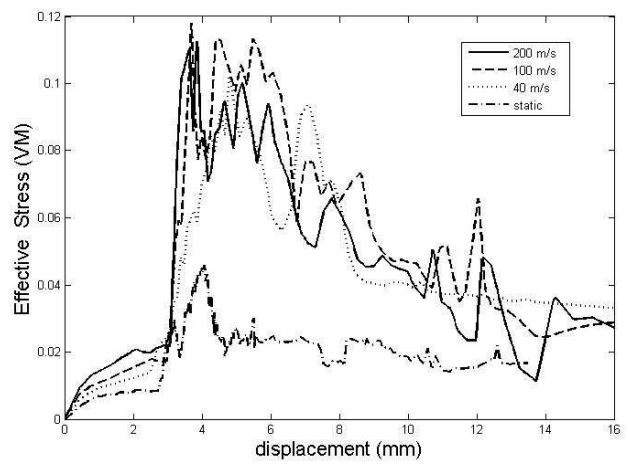

Fig. 10. The effective stress evolution vs. displacement under quasi-static and dynamic loading (static, 40, 100, $200 \mathrm{~m} / \mathrm{s}$ ).

\subsection{Analytical model}

On the basis of the above analysis of foam shock front, the induced enhancement of the perforation force increases. A simple analytical model can be derived to describe the impact perforation force enhancement. The simple model can be deduced from the impact piercing force enhancement model for the impact perforation of the sandwich panel based aluminum foam Cymat presented by Elnasri et al. [27] by removing the force needed to stretch the aluminum face sheet plate from the model. The impact force can then be written as:

$F_{p}=\frac{\pi D_{0}^{2}}{4}\left(\sigma_{n}+\frac{4 \gamma}{D_{C}}+\left(\rho_{0} v^{2}\right)^{\frac{m}{m+1)(k)^{m+1}}}\right)$

$\left(\sigma_{\mathrm{pl}}=4 \mathrm{MPa}\right)$ is the compression plateau stress, $\gamma$ is the tearing energy per unit newly created area $\left(6.8 \mathrm{KJ} / \mathrm{m}^{2}\right)$, $\rho 0$ is the density of the aluminum foam before crushing, $\mathrm{v}$ is the impact velocity, and $\mathrm{m}$ and $\mathrm{k}$ are the parameters of the densification curve $(\mathrm{m}=8.99, \mathrm{k}=48.9 \mathrm{MPa})$, Dc is the diameter of the volume of the crashed zone. Dc can be expressed by the following formula [28]:

$$
D_{C}=D+2(1.39 * z * \tan \alpha)
$$

where $\mathrm{D}$ is the diameter of the perforator, $\mathrm{z}$ is the indentation depth, and $\alpha$ is the angle between the tearing line and the vertical axis. Here, we can use the value of the angle used in the indentation of the foam with a semi-spherical nose $\left(\alpha=10.31^{\circ}\right)$. Figure 11 showed a simplified scheme of the perforation processes and the parameters presented in Equation 2.

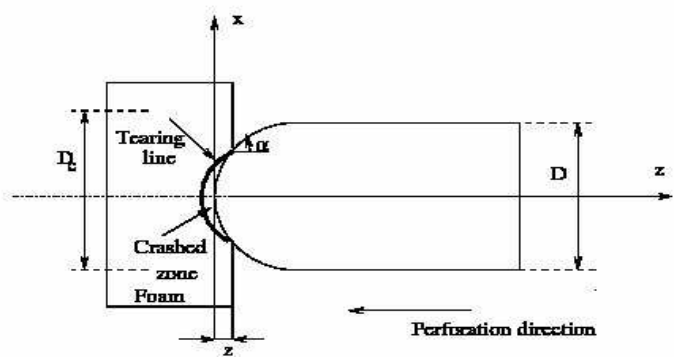

Fig. 11. Cross-section of an axisymmetric perforator with a semi-spherical nose.

The densification curve is defined by the initial yield stress $\sigma_{\mathrm{pl}}$, the power $\mathrm{m}$, and the coefficient $\mathrm{k}$ :

$$
\sigma=\sigma_{p l}+k \varepsilon^{m}
$$

A power law for the densification curve was proposed in order to overcome the quite arbitrary choice of the value of locking strain due to the exponential shape of the densification curve. The model was proposed according to the Rigid Perfectly Plastic Locking (RPPL) shock model. The dynamic perforation force from Equation 2 is compared with the corresponding results from the FE model and the experimental results $(\mathrm{v}=27,40 \mathrm{~m} / \mathrm{s})$ as shown in Figure 12. The analytical results of RPPL shock model with fixed locking strain $\left(\varepsilon_{\mathrm{d}}\right)$ (Equation 5) are also shown in the figure. 


$$
F_{P}=\frac{\pi D_{i}^{2}}{4}\left(\sigma_{p l}+\frac{4 \gamma}{D_{C}}+\frac{\rho_{g} v^{n}}{\epsilon_{d i}}\right)
$$

One can observe that the RPPL shock model with the power law of the densification curve improves the accuracy of the prediction, whereas the RPPL model with fixed locking strain overestimates the dynamic perforation load especially at higher impact velocities.

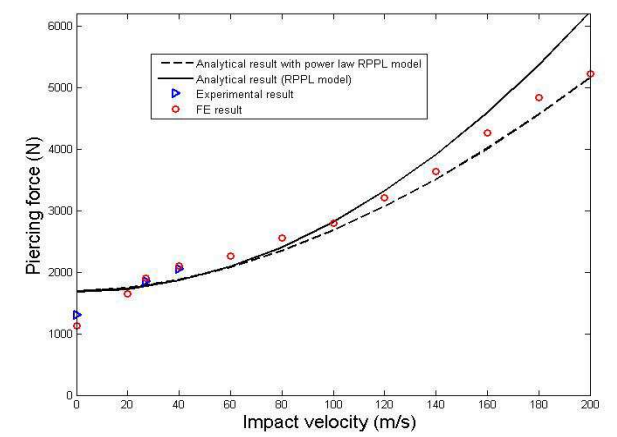

Fig. 12. Comparison between FE, analytical models and experimental results: impact perforation of Cymat foam.

\section{Conclusions}

Dynamic perforation of aluminum Cymat foam has been investigated experimentally and numerically. Impact perforation tests (up to around $40 \mathrm{~m} / \mathrm{s}$ ) were performed using an inverse perforation testing technique with a long, thin instrumented Hopkinson Bar. Such a measurement is missing in a classical free-flyingpenetrator-immobile-target scheme under impact loading and makes it possible to directly compare the impact perforation-force-displacement curves with the static ones. Quasi-static tests were also performed using a universal testing machine to study the effect of the loading rate on foam perforation. A significant enhancement of the perforation force of the foam under impact loading was found. To understand the cause of the enhancement in perforation force, a numerical model was developed using the LS-DYNA code. Two material models (honeycomb and Deshpande and Fleck) were tested. The following conclusions can be drawn:

- Comparison of force/displacement curves as well as effective stress/displacement curves with experiments shows that the developed models provide an accurate simulation of the perforation process of the tested aluminum Cymat foam.

- Virtual tests with different impact velocities of up $200 \mathrm{~m} / \mathrm{s}$ showed noticeable differences between quasi-static and impact loadings. A shock front effect is responsible for the observed enhancement of the perforation force.

- The honeycomb model (MAT_26) with the appropriate tensile failure criteria is more suitable to reproduce the perforation of the foam than the Deshpande and Fleck model (MAT_154) with volumetric failure strain criteria.

- An analytical model using a structure shock model with the assumption of power law densification was proposed to describe the enhancement of the impact perforation force and its results provide a prediction that is in agreement with the experimental and numerical results.

\section{References}

1. O.B. Olurin, N.A. Fleck, M.F. Ashby, SM. 43, (2003)

2. E. Andrews, G. Gioux, P., Onck, L.J. Gibson, IJMS 43 (2001)

3. V.I. Rizov, Mat. Des. J, 28, (2007)

4. J.U. Cho, S.J. Hong. S.K., Lee., C. Ch., JMSE 539 (2012)

5. A. Taherkhani, M. Sadighi, A.S. Vanini, , M.Z. Mahmoudabadi, JAST, 50 (2016)

6. S. Ramachandra, P., Sudheer, U. Ramamurty. SM, 49 (2003)

7. Q.M. Li, R.N. Maharaj, S.R. Reid, IJVD, 37 (2005)

8. G. Lu, B. J. Shena, W., Houa, D. Ruana, L.S. Ongb, IJMS, 50 (2008)

9. M.C. Shaw, T. Sata, IJMS, 8 (1996)

10. T.C. Triantafillou, L.J. Gibson, JEM, 116 (1990)

11. H.L. Schreyer, Q.H. Zuo, A.K. Maji, JEM., (1995)

12. V.S. Deshpande, N.A. Fleck, JMPS, 48,6 (2000)

13. D.C. Drucker, W. Prager, QAM., 10 (2) (1952)

14. A.L. Gurson, J. Eng. Mate. T., 99 (1) (1977)

15. J. Wen, Y. Huang, K.C. Hwang,., C. Liu, M. Li, IJP, 21 (2) (2005)

16. J. Zhang, Z. Lin, A. Wong, JEMT, 119 (3) (1997)

17. R.E. Miller, IJMS. 42 (4) (2000)

18. L.J. Gibson, M.F. Ashby, J. Zhang, T.C. Triantafillou, IJMS, 31 (9) (1989)

19. H. Fang., J. Bi., C. Zhang., Gutowski., E. Palta, Q. Wang., JNLM, 90 (2017)

20. A.G. Hanssen, O.S. Hopperstad, M. Langsethand,., H. Ilstad, IJMS, 44 (2002)

21. A. Reyes, O.S. Hopperstad, T. Berstad, A.G., Hanssen, M. Langseth, EJMS, 22 (2003)

22. H. Zhao, I. Elnasri, Y. Girard, IJIE , 34 (2007)

23. H. Zhao, I. Elnasri, S. Abdennadher, IJMS, 47 (2005)

24. I. Elnasri, S. Pattofatto, H. Zhao, H. Tsitsiris, F. Hild, Y. Girard, Y, JMPS, 55 (2007)

25. J.O. Hallquist, Theoretical Manual. LSTC., (1998)

26. LS-DYNA Keyword User's Manual, (2007)

27. I. Elnasri, H. Zhao, IJIE, 96 (2016)

28. E.A. Flores-Johnson, Q.M. Li., IJSS, 47 (2010) 